\title{
Frequency judgments of individual items after varying exposures in a multiple-item recognition learning list
}

\author{
DONALD H. KAUSLER, RUTH E. DALEZMAN, and ROBERT M. YADRICK \\ University of Missouri, Columbia, Missouri 65201
}

\begin{abstract}
Sets of pairs for a multiple-item recognition learning task varied in their number of exposures (one, two, and four) during a single extended study trial. The test phase required frequency of exposure judgments of individual items (i.e., prior right and wrong items). In agreement with frequency analyses of multiple-item recognition learning, frequency judgments of right items were greater than judgments of wrong items at each exposure level. Judgments of both item types increased as the number of pretest exposures increased, and the disparity between item types also increased with increases in exposure. Individual differences in frequency judgments were greater for wrong items than for right items.
\end{abstract}

Implicit in frequency analyses of multiple-item recognition, or verbal discrimination, learning (Ekstrand, Wallace, \& Underwood, 1966; Kausler, Pavur, \& Yadrick, 1975) are the assumptions that variation in pretest exposure produces variation in frequency values for both right and wrong items and that magnitude of these frequency values for right items is greater than the magnitude for wrong items at each level of pretest exposure. In addition, the disparity favoring right items is assumed to increase progressively as the number of pretest exposures increases. Nevertheless, evidence regarding the nature of the covariations between frequency of exposure and frequency values in multipleitem recognition learning is quite limited. Wallace, Murphy, and Sawyer (1973) obtained subjective frequency ratings for right and wrong items after three successive study trials on a verbal discrimination list, and both Rowe (1975) and Wallace, Sawyer, Murphy, and Robertson (1976) recorded overt rehearsals of items during study trials that alternated with pairwise test trials on a verbal discrimination list. However, none of these studies attempted to determine the covariation between item exposure and the frequency values of right vs. wrong items. When a study list is composed of individual items that vary in frequency of exposure, an effective means of determining the nature of the covariation between frequency of occurrence and frequency value is to require subjects to make absolute frequency judgments of estimates (e.g., Begg, 1974; Rose \& Rowe, 1976). Such frequency judgments presumably reflect the underlying frequency values of items at each level of pretest exposure. A procedure employed in a recent study by Kausler, Dalezman, and Yadrick (in press) is readily adaptable for use in a frequency judgment task

This study was supported in part by National Science Foundation Grant BMS75-05007 awarded to the first author. in which both right and wrong items vary in their frequency of occurrence. This adaptation was employed in the present experiment as a means of determining the covariation between frequency of exposure and frequency values for right vs. wrong items.

The procedure calls for an extended study trial in which pairs are varied in their number of pretest exposures (one, two, or four). That is, subjects receive a heterogeneous list in which some items are presented once, some twice, and some four times, with separation of repetitions. A test trial then follows the single study trial. In the earlier experiment subjects were required on the test trial to identify individual right and wrong items in terms of both their oldness and newness and their prior function in the study list. For the present modification subjects were required to make frequency judgments of individual right and wrong items after anticipating a paired item test trial in which right item members were to be identified.

An additional problem of concern was the difference, if any, between the variabilities of frequency values for right and wrong items across varying levels of pretest exposure. Kausler and Yadrick (1977) offered reasons for expecting the variability to be greater for right items than for wrong items at each exposure level. The present frequency judgment task provided a means of estimating the extent of these differences in variability.

\section{METHOD}

\section{Subjects}

The subjects were 120 introductory psychology students, none of whom had participated in prior verbal learning experiments. They were assigned in random blocks to 12 groups.

Design and Materials

Of the 18 experimental pairs in the study list, 6 were exposed once, 6 twice, and 6 four times. There were also five filler pairs 
in the study list, each exposed once (two at the beginning of the list and three at the end), that controlled for primacy and recency effects and were excluded from the test list. The test list contained 54 individual items: 18 right items $(6$ at each exposure level) of the study list, 18 wrong items (6 at each exposure level), and 18 control, or new, items that had not been included in the study list.

The materials were identical to those employed by Kausler et al. (in press). They called for four different sets of pairs, with each set being divided into three subsets of six pairs. Three groups of subjects received each set variant, with the groups differing in terms of the specific subsets receiving one, two, and four study trial exposures. A given pair was exposed once for one group, twice for a second group, and four times for a third group. The design required 12 groups of subjects $(4$ sets $\times 3$ subset variations). With this design, each of 72 experimental words appeared as a right item for 10 subjects at each level of pretest exposure. The new items for a given group consisted of words selected from the sets that were not used to construct that group's study list. Each of the 72 experimental words served as a new test item for 30 subjects.

\section{Procedure}

With one exception, the procedure followed that of Kausler et al. (in press) in terms of general instructions (inducing the expectancy of a standard pairwise test), pacing conditions (3-sec rate for pairs in the study phase and 6-sec rate for individual items in the test phase), and format of the test phase (recording item decisions on an answer sheet). Subjects were also informed in advance that some pairs in the study list would be shown more than once. The exception concerned the nature of the test phase. After being informed that their test phase would depart from the usual paired item test, the subjects were told that the actual test would consist of estimating the frequency with which each individual test item had been exposed during the study phase. They were told further that some of the test items would be new (i.e., zero frequency) and that the frequency of the old items varied from one to four.

\section{RESULTS AND DISCUSSION}

For each of the 120 subjects the mean frequency judgment was determined separately for the six right items and the six wrong items that had been presented at each of the three levels of pretest exposure. The overall means of the individual mean values, together with their standard deviations, are given in Table 1. Each subject's mean frequency value was also determined for his 18 new items. The overall mean of the individual means was .35 (standard deviation $=.29$ ).

Table 1

Summary Statistics for Mean Frequency Judgments and Mean Within-Subjects Standard Deviation Scores

\begin{tabular}{|c|c|c|c|c|c|c|}
\hline \multirow{3}{*}{$\begin{array}{l}\text { Item } \\
\text { Type }\end{array}$} & \multicolumn{6}{|c|}{ Pretest Exposures } \\
\hline & \multicolumn{2}{|c|}{1} & \multicolumn{2}{|c|}{2} & \multicolumn{2}{|c|}{4} \\
\hline & M & SD & $\mathbf{M}$ & SD & M & SD \\
\hline & \multicolumn{6}{|c|}{ Mean Frequency Judgments } \\
\hline \multirow{3}{*}{$\begin{array}{l}\text { Right } \\
\text { Wrong }\end{array}$} & 1.39 & .45 & 2.30 & .56 & 3.17 & .51 \\
\hline & 1.05 & .54 & 1.74 & .66 & 2.41 & .76 \\
\hline & \multicolumn{6}{|c|}{ Mean Standard Deviation Scores } \\
\hline Right & .77 & .38 & .97 & .40 & .77 & .35 \\
\hline Wrong & .87 & .36 & 1.05 & .40 & 1.10 & .38 \\
\hline
\end{tabular}

A 2 (item type) by 3 (pretest exposure) analysis of variance (MSe $=.21, \mathrm{p}$ set at .05 for all analyses) revealed significant main effects for item type $[F(1,595)=$ 257.60] and number of exposures $[F(2,595)=688.09]$ and a significant Item Type by Number of Exposures interaction $[F(2,595)=12.53]$. From Table 1 it may be seen that right items were judged to have occurred more frequently than wrong items at each level of pretest exposure and that judged frequency increased for both types of items as the actual frequency of occurrence increased. However, the significant interaction reflects the fact that the rate of increase over increasing occurrences was greater for right items than for wrong items. Assuming that judged frequency is mediated by an item's accrued frequency value, this interaction effect is in agreement with a basic premise of the Ekstrand et al. frequency theory, namely, that right items accrue frequency units at a faster rate than do wrong items. Moreover, the mean values are in agreement with the Kausler et al. (in press) conceptualization of partially overlapping distributions of frequency values for right and wrong items from a heterogeneous, or mixed exposure, list. The preponderance of items at the lower end of each distribution consists of items exposed once and the preponderance of items at the upper end of each distribution consists of items exposed four times. Finally, it should be noted that subjects tended to overestimate the frequency of both right and wrong items that had a low frequency of occurrence and to underestimate the frequency of both right and wrong items that had a high frequency of occurrence. A comparable effect has been commonly reported for frequency judgment tasks in which individual items receive varying occurrences in the study list (e.g., Begg, 1974).

As an initial step in analyzing differences in variability between right and wrong items, the standard deviation of the frequency judgments given to each set of items (e.g., the right items exposed once) was determined separately for each individual subject. The overall means of these individual standard deviations, together with their standard deviations, are given in Table 1 . A 2 by 3 within-subjects analysis of the variability scores $(\mathrm{MSe}=.113)$ yielded significant main effects for item type $[F(1,595)=47.33]$ and number of exposures $[F(2,595)=18.67]$, along with a significant Item Type by Number of Exposures interaction $[F(2,595)=10.04]$. Surprisingly, the variability of frequency values associated with wrong items appears to be greater than the variability associated with right items. Moreover, the variability associated with wrong items appears to increase with increasing exposures, whereas the variability associated with right items shows no apparent trend over increasing exposures. Kausler and Yadrick (1977) had reasoned that right items are likely to display greater variability than wrong items because right items receive both rehearsal responses and perceptual responses, while wrong items are restricted 
largely to perceptual responses. Since the rate of rehearsal responses is likely to be more variable than the rate of perceptual responses, an added source of variance seemingly exists for right items that is greatly diminished for wrong items. By contrast, the present results suggest that the added source of variance rests largely with wrong items. The nature of this source remains unknown. However, a likely candidate is the variability associated with the contextual relevance of a given wrong item. Some wrong items may play an important contextual role in relation to the elaborative rehearsal given to their accompanying right items (Kausler et al., in press). Consequently, these wrong items are likely to receive multiple responses via their co-rehearsal with right items. On the other hand, other wrong items provide little in the way of an elaborative context, and they are therefore likely to be largely ignored. Of course, it is also conceivable that the difference in variability simply reflects differential ceiling effects for the frequency values of right and wrong items.

\section{REFERENCES}

BEGG. I. Estimation of word frequency in continuous and discrete tasks. Journal of Experimental Psychology, 1974, 102, 10461052.
Ekstrand, B. R., Wallace, W. P., \& Underwood, B. J. A frequency theory of verbal discrimination learning. Psychology Review, 1966, 73, 566-578.

Kausler, D. H., Dalezman, R. E., \& Yadrick, R. M. Item identifications following varying presentations of pairs on a heterogenous multiple-item recognition learning task. Journal of Experimental Psychology: Human Learning and Memory, in press.

Kausler, D. H., Pavur, E. J., JR., \& Yadrick, R. M. Single-item recognition following a verbal discrimination study trial. Memory \& Cognition, 1975, 3, 135-139.

KAUSLER, D. H., \& Y.ADRICK, R. M. Item identifications following varying study trials on a multiple-item recognition learning task. Journal of Experimental Psychology : Human Learning and Memory, 1977, 3, 203-210.

Rose, R. J., \& RowE, E. J. Effects of orienting task and spacing of repetitions on frequency judgments. Journal of Experimental Psychology: Human Learning and Memory, 1976, 2, 142-152.

RowE, E. J. The effect of imagery on rehearsal strategies in verbaldiscrimination learning. American Journal of Psychology, 1975, 88, 431-442.

Wallace, W. P., Murphy, M. D., \& Sawyer, T. J. Imagery and frequency in verbal discrimination learning. Journal of Experimental Psychology, 1973, 101, 201-219.

(Received for publication August 19, 1977.) 